\title{
Novel calcium-sensing receptor cytoplasmic tail deletion mutation causing autosomal dominant hypocalcemia: molecular and clinical study
}

\author{
Barbora Obermannova, Zdenek Sumnik, Petra Dusatkova, Ondrej Cinek, \\ Michael Grant ${ }^{1}$, Jan Lebl and Geoffrey N Hendy ${ }^{2,3}$
}

Department of Pediatrics, Second Faculty of Medicine, Charles University in Prague, University Hospital Motol V Uvalu 84, CZ-150 06 Prague, Czech Republic, 'Lady Davis Institute for Medical Research, SMBD-Jewish General Hospital, McGill University, Montréal, Québec, Canada H3T 1E2, ²Experimental Therapeutics and Metabolism, Room No. EM1.3226 RI-McGill University Health Centre Glen Site, 1001 Décarie Boulevard, Montréal, Québec, Canada H4A 3J1 and ${ }^{3}$ Departments of Medicine, Physiology, and Human Genetics, McGill University, Montréal, Québec, Canada H4A 3J1
Correspondence

should be addressed to

G N Hendy or B Obermannova Emails

geoffrey.hendy@mcgill.ca or obermannova@seznam.cz

\section{Abstract}

Objective: Autosomal dominant hypocalcemia (ADH) is a rare disorder caused by activating mutations of the calcium-sensing receptor (CASR). The treatment of ADH patients with $1 \alpha$-hydroxylated vitamin $D$ derivatives can cause hypercalciuria leading to nephrocalcinosis.

Design and methods: We studied a girl who presented with hypoparathyroidism and asymptomatic hypocalcemia at age 2.5 years. Mutations of CASR were investigated by DNA sequencing. Functional analyses of mutant and WT CASRs were done in transiently transfected human embryonic kidney (HEK293) cells.

Results: The proband and her father are heterozygous for an eight-nucleotide deletion c.2703_2710delCCTTGGAG in the CASR encoding the intracellular domain of the protein. Transient expression of CASR constructs in kidney cells in vitro suggested greater cell surface expression of the mutant receptor with a left-shifted extracellular calcium dose-response curve relative to that of the WT receptor consistent with gain of function. Initial treatment of the patient with calcitriol led to increased urinary calcium excretion. Evaluation for mosaicism in the paternal grandparents of the proband was negative. Conclusions: We describe a novel naturally occurring deletion mutation within the CASR that apparently arose de novo in the father of the ADH proband. Functional analysis suggests that the cytoplasmic tail of the CASR contains determinants that regulate the attenuation of signal transduction. Early molecular analysis of the CASR gene in patients with isolated idiopathic hypoparathyroidism is recommended because of its relevance to clinical outcome and treatment choice. In ADH patients, calcium supplementation and low-dose cholecalciferol avoids hypocalcemic symptoms without compromising renal function.

\section{Introduction}

Isolated hypoparathyroidism is characterized by hypocalcemia associated with a low level of serum parathyroid hormone (PTH). Although most cases are sporadic, some have autosomal dominant, autosomal recessive or X-linked modes of inheritance (1). Linkage analyses of large families with autosomal dominant hypoparathyroidism mapped a candidate gene to chromosome 3q13 that harbors the calcium-sensing receptor $(C A S R)$ gene $(2,3)$. Soon after the cloning of the CASR (4), heterozygous activating mutations within its gene were reported as a cause of familial hypoparathyroidism (5). The elucidation of the molecular basis of this form of familial hypoparathyroidism with a dominant inheritance pattern has revealed a distinct clinical entity among the various forms of (c) 2016 European Society of Endocrinology Printed in Great Britain
Published by Bioscientifica Ltd. 
hypoparathyroidism, autosomal dominant hypocalcemia (ADH; MIM \#601198) (6, 7). ADH is a rare inherited disease that occurs clinically at any point during life time. Its estimated prevalence is 1/70 000 (8). The clinical presentation is variable, and the associated hypocalcemia is often asymptomatic. The biochemical features of this condition include typically mild-to-moderate, and occasionally more severe, hypocalcemia and hyperphosphatemia accompanied by a low or normal PTH serum level and often a paradoxically normal or elevated urinary calcium excretion rate despite a low serum calcium concentration $(6,7,9)$.

CASR belongs to a subfamily of $G$ protein-coupled receptors (GPCR) characterized by a very large extracellular ligand-binding domain (ECD) followed by a seven transmembrane-spanning domain, contributing to the receptor activation and a long carboxyl-terminal intracellular domain (ICD). The CASR is present on the cell surface as a homodimer, formed constitutively in the endoplasmic reticulum by intermolecular disulfide bonds as well as non-covalent interactions $(10,11,12)$. The ICD of the human CASR consists of 216 residues and has been shown to modulate several aspects of receptor function including receptor trafficking, level of cell surface expression, intracellular cell signaling and rate of desensitization $(13,14,15,16)$.

In the present study, we report a hypocalcemic patient who is heterozygous for a novel CASR mutation that while it deletes much of the CASR ICD is in fact expressed phenotypically as a gain of function mutant.

\section{Subjects and methods}

\section{Patients}

Seven members of a single family (see Fig. 1) were studied (two males and five females). Informed consent for genetic testing was obtained from all participants or their legal guardians in accordance with local institutional guidelines.

\section{Amplification of genomic DNA and sequence analysis of CASR}

Leukocyte DNA from venous blood samples from individuals I-1, I-2, II-2, II-4, III-1 and III-2 (Fig. 1), and buccal cell DNA from the deceased individual II-3 (Fig. 1) were isolated using standard methods. Twelve primer pairs were used to amplify exons 2-7 of CASR (encompassing the entire coding sequence), and these primers have been previously described $(5,17)$ except for $5^{\prime}$-GGTGCGTTGCAGCACCGCAGCTCA-3', which was used to replace the exon 7D forward primer. After gel purification, PCR products were directly sequenced (both strands) using a BigDye Terminator Ready Reaction Cycle Sequencing Kit (Applied Biosystems) and an ABI PRISM 377 sequencer (Applied Biosystems).

\section{Site-directed mutagenesis and transfection}

Mutated alleles, c.2703_2710delCCTTGGAG (present study), c.2682_3224del (18) and A877* (19) are designated hereafter as del2703_2710, del2682_3224 and A877X. The mutations were introduced into a c-Myc-tagged human CASR cDNA in pcDNA3.1 using our previously described methods (20). The previously characterized naturally occurring ADH CASR large cytoplasmic tail deletion (c.2682_3224del) mutant (18) and the engineered A877X mutant (19) were chosen as reference controls in our studies. The correctness of the constructs was confirmed by sequencing. Human embryonic kidney (HEK293) cells (kindly provided by NPS Pharmaceuticals, Inc., Salt Lake City, UT) were transfected with c-Myc-tagged human CASR cDNAs, WT or mutant, as described (9).

\section{Fluorescence immunocytochemistry and confocal microscopy}

In total, $48 \mathrm{~h}$ after transfection, PBS-washed cells were fixed in cold $4 \%$ paraformaldehyde/0.12 M sucrose. Cells were permeabilized with $0.2 \%$ Triton $\mathrm{X}-100$ in PBS for $15 \mathrm{~min}$. Washed cells were incubated in $6 \%$ goat serum for 30 min and then at $4{ }^{\circ} \mathrm{C}$ overnight with a c-Myc MAB (9E10) at a 1:100 dilution. Triton X-100 (0.1\%) was added to the solutions containing permeabilized cells. Washed cells were incubated for $1.5 \mathrm{~h}$ with a goat anti-mouse Cy3conjugated antibody (Jackson Immunoresearch Laboratories, Inc., West Grove, PA, USA). Slides were mounted with Permafluor mounting medium, dried and visualized by confocal microscopy (Carl Zeiss LSM 410 laser scanning microscope, NY) (12).

\section{Western blot analysis}

Western blot analysis was conducted to assess whole-cell extracts of HEK293 cells transiently transfected with WT and both mutant c-Myc-tagged CASR cDNAs del2703_2710 and del2682_3224. Proteins were isolated from HEK293 cells and subjected to SDS-PAGE on a 5-9\% linear gradient gel, followed by western blotting as described previously (9). 


\section{MAPK assay}

The ability of mutated receptors to respond to extracellular calcium ions was compared to that of the WT receptor. Relative activity was assessed by phosphorylation of ERK1/2, a protein targeted by MAPK pathways (21). HEK293 cells were treated with increasing $\mathrm{CaCl}_{2}$ concentrations $(0.5-10 \mathrm{mM})$ for $5 \mathrm{~min}$. Whole-cell extracts were

A

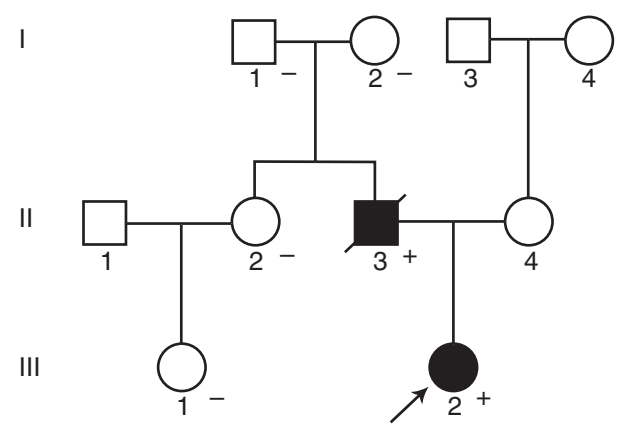

B
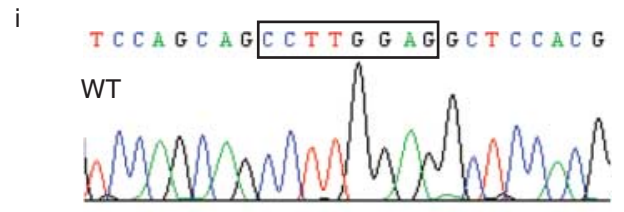

ii

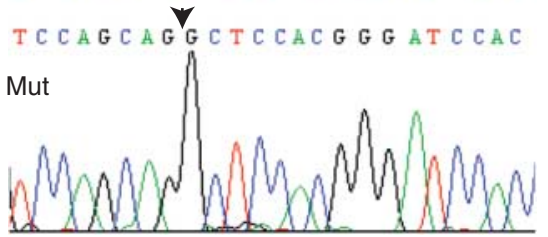

C

Codon number $\quad 900 \quad 901 \quad 902903 \quad 904 \quad 905$ del 2703-2710 AGC AG GC TCC

WT AGC AGC CTT GGA GGC TCC

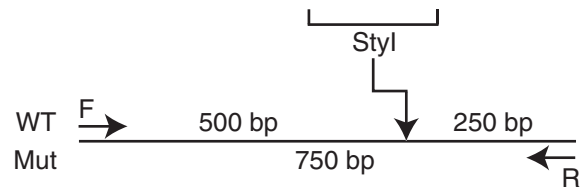

D

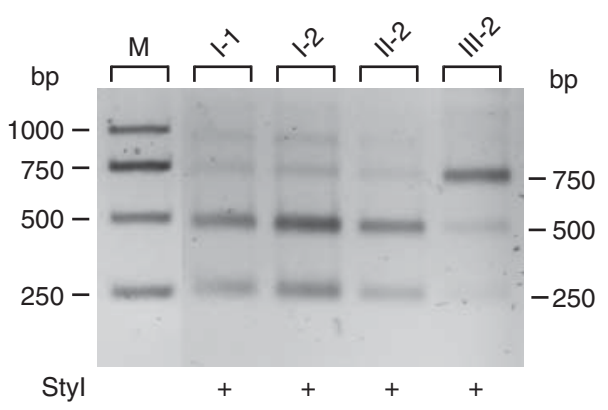

prepared, and aliquots were separated by 10\% SDS-PAGE and analyzed for the expression of phosphorylated and total ERK1/2 by immunoblotting with a PhosphoPlus p44/42 MAPK (Thr202/Tyr204) antibody kit (Cell Signaling Technology, Beverly, MA, USA), according to the manufacturer's protocol. Scion Image-National Institutes of Health image processing and analysis program (http:// rsb.info.nih.gov/nih-image/) was used for signal densitometry. The ratios of the phosphorylated to nonphosphorylated ERK1/2 signals at various extracellular calcium concentrations were calculated first and then normalized to the ratio of phosphorylated to nonphosphorylated ERK1/2 at $0.5 \mathrm{mM} \mathrm{Ca}^{++}$as described previously (22), and dose-response curves were plotted.

\section{Results \\ Patients}

The proband (III-2; Fig. 1) was a baby girl born by Caesarian section at 38 weeks after a normal pregnancy of her mother, a 28-year-old healthy female (II-4; Fig. 1A). The parents were non-consanguineous and Caucasian. The birth weight and length were $3900 \mathrm{~g}$ and $50 \mathrm{~cm}$ respectively, and the perinatal history was uneventful. The baby was breast-fed, thrived well and was provided with

\section{Figure 1}

(A) Pedigree of the family with ADH. Clinical status is indicated by open symbols (unaffected or status not known) and solid symbols (ADH). Further clinical details are given in Table 1. The proband is indicated by the arrow. $(+)$ presence and $(-)$ absence of a mutated CASR allele. (B) Direct sequence analysis of genomic DNA of patient III-2 revealed a heterozygous deletion mutation (not shown) that was confirmed by sequencing individual subclones of the exon 7 PCR product. Sequence chromatograms: i) WT allele. The nucleotides deleted in the mutated allele are boxed: ii) mutated allele. The arrowhead indicates the deletion point. (C) WT and mutant sequences of part of exon 7. The restriction enzyme Styl recognition site present in the WT but lost in the mutant del2703-2710 is bracketed. The Styl site in the WT is shown on the restriction map of the exon 7 amplicon. (D) Gel electrophoretic separation of Styl restriction digests of the exon 7 PCR product in family members confirmed the presence of the mutation in individual III-2 and its absence in individuals I-1, I-2 and II-2. Lane M, DNA markers with sizes to the left of the gel. Undigested and Styl-digested exon 7 amplicon sizes are shown to the right. 
vitamin $\mathrm{D}_{3}$ supplementation at the standard dosage (600 IU/day). Psychomotor development was normal, with no evidence of tetany or seizures. The proband was clinically evaluated at 2.5 years of age because her father (II-3; Fig. 1A) had been diagnosed with hypoparathyroidism (see below). Laboratory work-up of the girl showed hypocalcemia, hyperphosphatemia, a low PTH level and hypocalciuria (Table 1; urine calcium $\mathrm{mmol} / \mathrm{day}$ ). The serum 25-hydroxycholecalciferol level was normal. Clinically, the girl did not demonstrate paresthesia, cramps or tetany. However, increased neuromuscular irritability was demonstrated by Chvostek and Trousseau signs. A prolonged QTc interval was found by electrocardiography. Nephrocalcinosis was excluded by renal ultrasonography.

The father of the proband (II-3; Fig. 1A) was examined for tetany and paresthesia at the age of 30 years. Laboratory work-up revealed hypocalcemia, hyperphosphatemia, an inappropriately normal serum PTH level and normocalciuria (Table 1). Magnetic resonance imaging of the brain revealed calcifications of the basal ganglia and osteoarthrosis with calcifications of the shoulder joints. Nephrocalcinosis was not evident. Treatment was initiated with a vitamin $\mathrm{D}_{3}$ derivative, dihydrotachysterol, at $600 \mathrm{IU} /$ day and oral calcium at $1500 \mathrm{mg} /$ day. At the age of 33 years, he died suddenly due to an accident. The paternal grandparents (I-1 and I-2; Fig. 1A) had normal calcium and phosphate levels. The father's mother (I-2; Fig. 1A) was undergoing treatment for urolithiasis. The father's sister (II-2; Fig. 1) and her daughter (III-1; Fig. 1A) were clinically healthy with respect to calcium and phosphate metabolism.

The proband's mother (II-4; Fig. 1A) had an unremarkable health history. Her serum calcium, phosphate, magnesium, PTH and 25-hydroxyvitamin $\mathrm{D}_{3}$ levels were normal, as well as her calcium excretion rate. There was no evidence of any calcium or phosphate disorder on the maternal side of the family.

\section{PCR and DNA sequence analysis of the mutation}

Direct sequence analysis (not shown) of PCR-amplified CASR exons in the proband (III-2) and her father (II-3) identified a novel heterozygous CASR mutation encompassing loss of eight nucleotides in exon 7, c.2703 2710delCCTTGGAG. Examination of subclones of the WT and mutant alleles revealed their sequences (Fig. 1B). This deletion leads to a frame shift, introduction of non-CASR amino acid sequence with premature arrest of the synthesis of the mutated protein - p.S901del/fsX977. In individuals III-1, II-1, II-2, II-4, I-1 and I-2, direct sequence analysis of CASR exon 7 confirmed homozygosity for the WT allele. The genotypes of particular family members are displayed in Fig. 1A. In addition, the presence of this mutation abolished a StyI restriction site in the CASR exon 7 amplicon allowing for a convenient diagnostic test of the presence or absence of the mutation in family members (see Fig. 1C and D).

\section{Fluorescence immunocytochemistry and confocal microscopy}

The presence of cell surface staining (positive staining indicates normal receptor maturation and trafficking to the plasma membrane) was performed using non-permeabilized cells, and the expression of receptors undergoing maturation and trafficking within cells was assessed using permeabilized cells. Non-permeabilized cells transfected with WT receptor showed strong staining at the cell surface. Permeabilization of these cells revealed additional perinuclear staining associated with the endoplasmic reticulum and Golgi apparatus (Fig. 2). Nonpermeabilized and permeabilized cells transfected with mutated CASRs showed similar patterns as the WT, indicating normal trafficking of the mutant CASRs from the endoplasmic reticulum to the membrane (Fig. 2).

Table 1 Baseline biochemical values in the proband (III-2), her father (II-2) and her mother (II-4).

\begin{tabular}{|c|c|c|c|c|c|c|c|c|}
\hline Pedigree & $\begin{array}{l}\text { Serum total } \\
\text { calcium }(2.05- \\
2.54 \mathrm{mmol} / \mathrm{l})\end{array}$ & $\begin{array}{c}\text { Serum-ionized } \\
\text { calcium }(1.20- \\
1.38 \mathrm{mmol} / \mathrm{l})\end{array}$ & $\begin{array}{c}\text { Serum } \\
\text { phosphate } \\
(0.65-1.61 \\
\mathrm{mmol} / \mathrm{l})^{\mathrm{a}}\end{array}$ & $\begin{array}{c}\text { Serum } \\
\text { magnesium } \\
(0.78-0.99 \\
\mathrm{mmol} / \mathrm{l})\end{array}$ & $\begin{array}{c}\text { Serum PTH } \\
(1.30-7.60 \\
\mathrm{pmol} / \mathrm{l})\end{array}$ & $\begin{array}{c}\text { Serum } \\
\text { 25(OH)D } \\
(50-250 \mathrm{nmol} / \mathrm{l})\end{array}$ & $\begin{array}{c}\text { Diurnal } \\
\text { urinary Ca } \\
(2.4-7.2 \mathrm{mmol} / \\
\text { day })^{\mathrm{b}}\end{array}$ & $\begin{array}{c}\text { Urinary Ca } \\
\text { to } \mathbf{C r} \text { index } \\
\text { (to } 0.59 \mathrm{mmol} / \\
\mathrm{mmol} \text { ) }\end{array}$ \\
\hline III-2 & 1.96 & 0.89 & 2.78 & 0.98 & 1.01 & 107.00 & 0.40 & 0.15 \\
\hline $11-3$ & 1.74 & ND & 2.04 & ND & 1.40 & ND & 5.81 & ND \\
\hline II-4 & 2.34 & ND & 1.15 & 0.83 & 4.24 & 131.00 & 2.80 & 0.51 \\
\hline $\begin{array}{l}\text { ND, not de } \\
{ }^{\mathrm{a}} \text { Normal ra } \\
{ }^{\mathrm{b}} \text { Normal ra }\end{array}$ & $\begin{array}{l}\text { rmined. } \\
\text { ge for infants ( } \\
\text { ge for infants ( }\end{array}$ & $\begin{array}{l} \\
-1.90) \text {. } \\
-4.00) \text {. }\end{array}$ & & & & & & \\
\hline
\end{tabular}



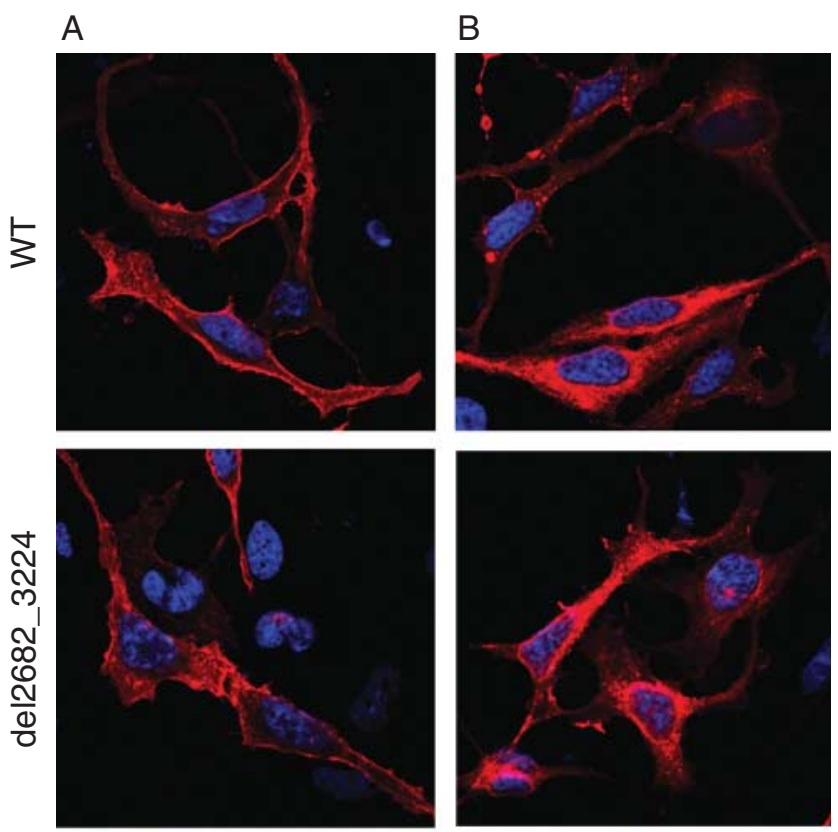

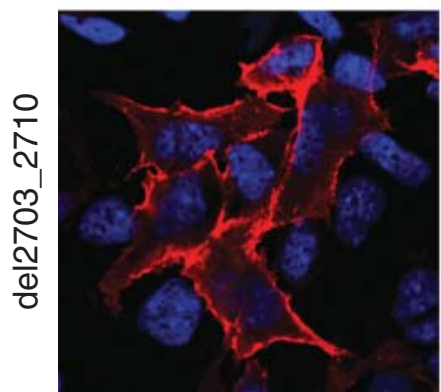

Non-permeabilized

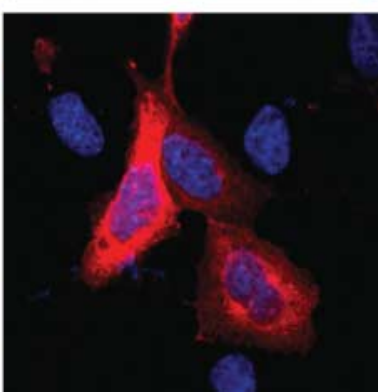

Permeabilized

\section{Figure 2}

Plasma membrane and intracellular expression of WT and mutant CASRs in transfected HEK293 cells. Fluorescence immunocytochemistry and confocal microscopy were performed in HEK293 cells transiently transfected with WT or mutant (del2682_3224 or del2703_2710) c-Myc-tagged CASR CDNAs. Immunostaining was done with c-Myc MAB 9E10, and detection was made with goat anti-mouse fluorescein isothiocyanate-conjugated secondary antibody. Examples of fields of non-permeabilized (A) and permeabilized (B) cells are shown.

\section{Western blot analysis of transiently expressed WT and mutant CASRs in HEK293 cells}

The different species of the WT receptor observed upon western blot analysis (Fig. 3A) are the monomeric immature glycosylated (140 kDa), mature glycosylated $(160 \mathrm{kDa})$ and dimeric $(>300 \mathrm{kDa})$ forms. Both the del2682_3224 and del2703_2710 mutants have all these similar forms of the receptor, but they migrate at a faster
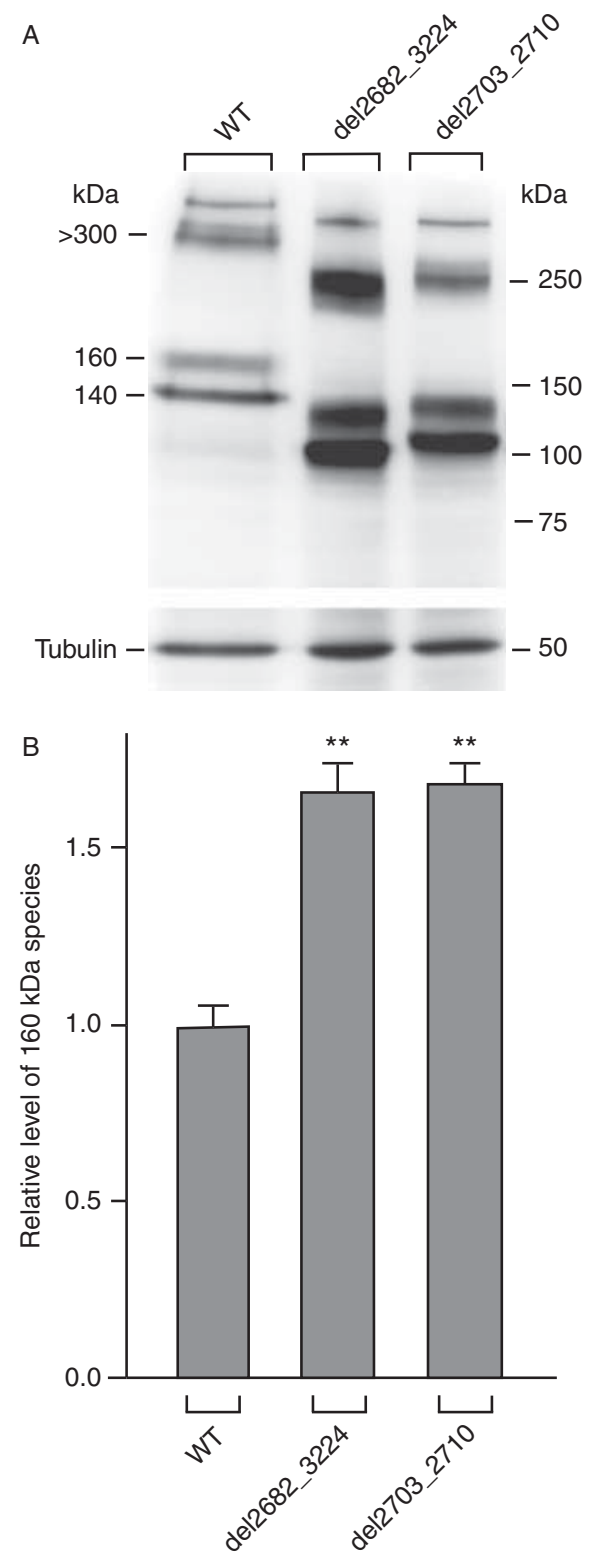

Figure 3

(A) Western blot analysis of cell extracts of HEK293 cells transiently transfected with WT or mutant (del2682_3224 or del2703_2710) c-Myc-tagged CASR cDNAs. Recombinant proteins were stained with c-Myc MAB 9E10, and endogenous proteins were stained with a $\beta$-tubulin antibody. Sizes of CASR WT species are shown on the left, and molecular weight markers are shown on the right. (B) Levels of the CASR 160-kDa WT mature monomeric and the equivalent mutant species relative to $\beta$-tubulin were determined by densitometry. The levels of the mutant mature monomeric species are shown relative to that of WT (set at 1.0). Values shown are the means ( \pm S.E.M.) of three replicates. ${ }^{*} P<0.01$ compared with WT. 
mobility on the gel consistent with their truncated sizes relative to WT. The result with the del2682_3224 mutant is fully consistent with a previous study (18) that documented higher levels of this mutant at the plasma membrane. The higher overall levels as well as specifically the mature monomeric species in the del2703_2710 and del2682_3224 mutants (Fig. 3B) provide evidence that like the del2682_3224 mutant, the del2703_2710 mutant is also more highly expressed at the cell surface.

\section{MAPK responsiveness of mutant CASRs to extracellular calcium}

The ability of the mutant receptors relative to WT receptor to respond to extracellular calcium was assessed in a MAPK ERK1/2 assay following transient expression in HEK293 cells. Compared with WT CASR, the positive control mutated receptor del2682_3224 exhibited a left-shifted dose-response curve with a reduced $\mathrm{EC}_{50}$ (the level of extracellular $\mathrm{Ca}$ producing half of the maximal intracellular response) fully consistent with a previous study in which the ability of extracellular calcium to increase intracellular calcium was evaluated (18). Similarly the novel del2703_2710 mutant demonstrated a left-shifted dose-response curve with a reduced $\mathrm{EC}_{50}$ relative to WT (Fig. 4). The negative control mutant A877X demonstrated barely $10 \%$ of the activity of the WT even at the maximum extracellular calcium dose. This is fully consistent with our previous study with this mutant in which intracellular calcium changes were measured (19).

\section{Subcloning of CASR exon 7 and restriction enzyme analysis}

Subclones of the leukocyte DNA CASR exon 7 amplicon inserted into a TA cloning vector were distinguished by StyI/EcoRI restriction enzyme analysis (Fig. 5). The $\mathrm{WT} /$ mutant ratios detected were as follows: I-1, 40:0 (100\% WT/0\% mutant); I-2, 99:0 (100\% WT/0\% mutant); and III-2, 30:35 (46\% WT/54\% mutant). Therefore, the proband (III-2) was confirmed as being heterozygous for the mutation and the paternal grandparents (I-1 and I-2) as both homozygous for the WT allele, thus providing no evidence for mosaicism.

\section{Influence of treatment on proband's calciuria}

At the age of 2.5 years, the proband was hypocalcemic but normocalciuric (Table 2; urinary Ca to Cr index); therefore, calcitriol supplementation (17 ng/kg per day) was initiated
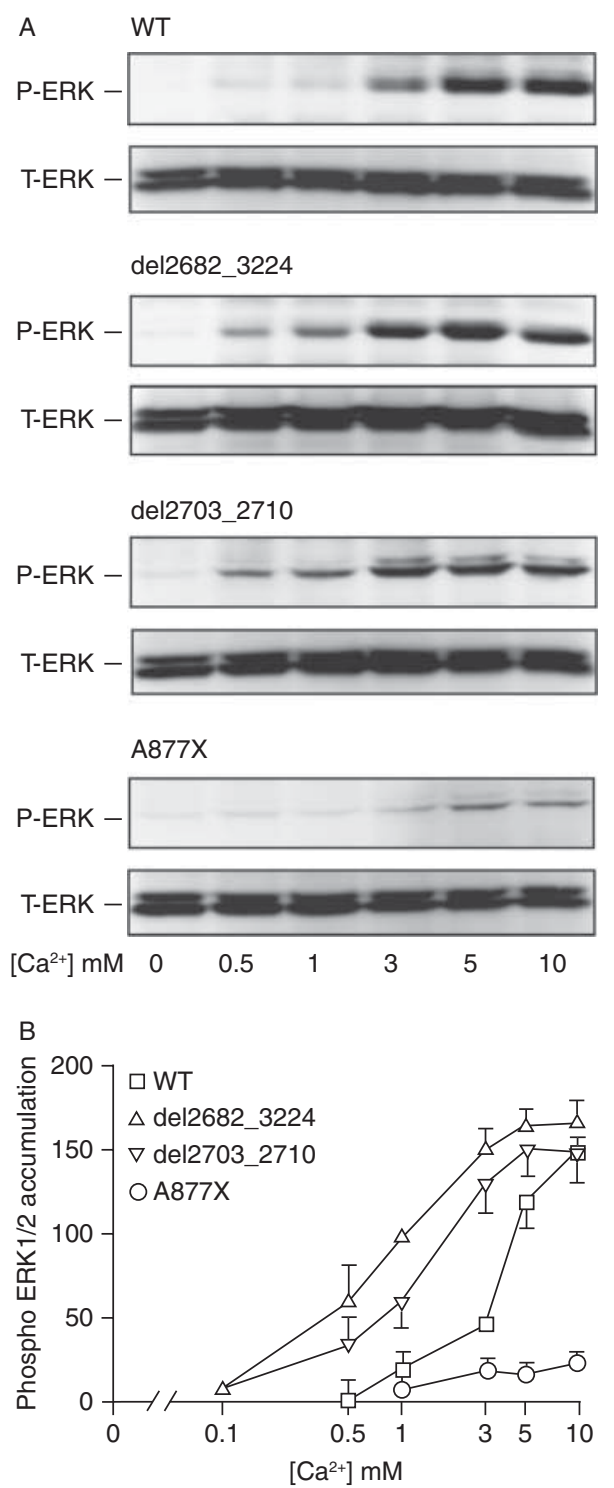

\section{Figure 4}

(A) Extracellular $\mathrm{Ca}^{2+}$-dependent activation of endogenous ERK1/2 phosphorylation in HEK293 cells transiently transfected with WT or mutant (del2682_3224, del2703_2710 or A877X) c-Myc-tagged CASR cDNAs. The transfected cells were exposed to $0.1-10 \mathrm{mM}$ calcium for $5 \mathrm{~min}$, and extracts were made and immunoblotted. Western blots were developed with antibodies against either phospho or total ERK1/2 (labeled as P-ERK or T-ERK respectively). Representative results are shown for WT and mutants. (B) Protein signals were quantitated by densitometry, and the ratios of phospho ERK $1 / 2$ to total ERK1/2 were determined and normalized to the values obtained in cells exposed to $0.5 \mathrm{mM}$ calcium (phospho ERK1/2 accumulation). Values shown are the mean ( \pm s.E.M.) of four replicates and representative of three independent experiments. 


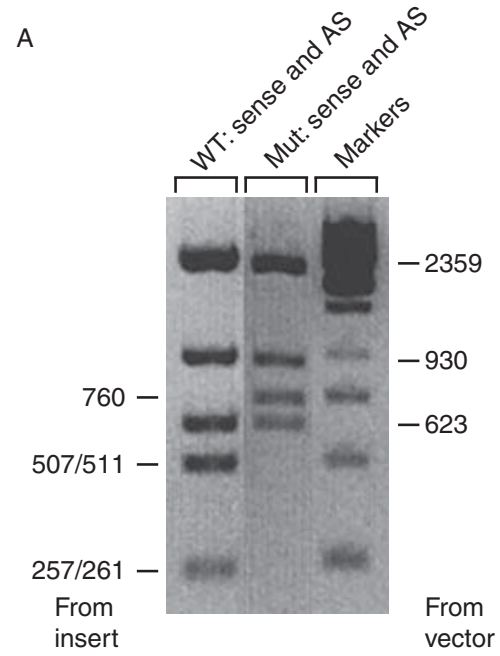

B without additional calcium. After 3 months of treatment, the proband exhibited persistent hypocalcemia and hyperphosphatemia, with an undetectable serum PTH level. The urinary excretion rate remained relatively low; therefore, the calcitriol supplementation dosage was doubled (to $34 \mathrm{ng} / \mathrm{kg}$ per day). At the age 3.75 years, the proband remained hypocalcemic, and the calcium urinary excretion rate was increased to a hypercalciuric level (Table 2). Therefore, the calcitriol treatment was switched to calcium supplementation (600 $\mathrm{mg}$ /day) in combination with a low dose of cholecalciferol (200 IU/day). After an additional 3 months, the proband was normocalciuric. This treatment has been continued up to the present age of 7 years and has resulted in stable serum calcium and PTH levels and normocalciuria (Table 2). The girl has no clinical symptoms of hypocalcemia; her renal function is normal, and nephrocalcinosis has been excluded by renal ultrasound.

\section{Discussion}

We have identified a novel heterozygous mutation, del2703_2710, in the C-tail of the CASR accounting for the hypoparathyroidism/hypocalcemia of the proband and her father. Hence, they have ADH type 1. Functional analysis of the mutant receptor confirmed its gain-offunction properties relative to the WT receptor. The present mutation, S901del/fsX977, can be compared with other activating mutations found in the CASR ICD, S895_V1075del (18), K897ins/fsX979 (23) and P910del/ fsX938 (24) in which significant parts of the CASR C-tail are deleted or changed to a shortened mutated sequence.

\section{Figure 5}

Search for evidence of mosaicism for the CASR mutation in clinically unaffected individuals I-1 and I-2 (see Fig. 1A) by analysis of subcloned PCR amplicons. (A) DNA fragment patterns of Styl/EcoRI-digested recombinant plasmids representing either WT or mutant CASR exon 7 cloned into the PCR2.1-TOPO vector in either sense or antisense orientation. Only one lane is shown for WT: sense and antisense, and only one for mutant: sense and antisense, as in each case (sense and antisense), the restriction patterns are indistinguishable. The sizes of fragments in bp derived from the insert are shown to the left, and those derived from the vector are shown to the right. (B) Styl/EcoRI (S/E) restriction map of the PCR2.1-TOPO vector and the four alternative inserts. (C) Percentage of clones obtained after subcloning the CASR exon 7 amplicon from leukocyte DNA of individuals I-1, I-2 and III-2 (see text for details). 


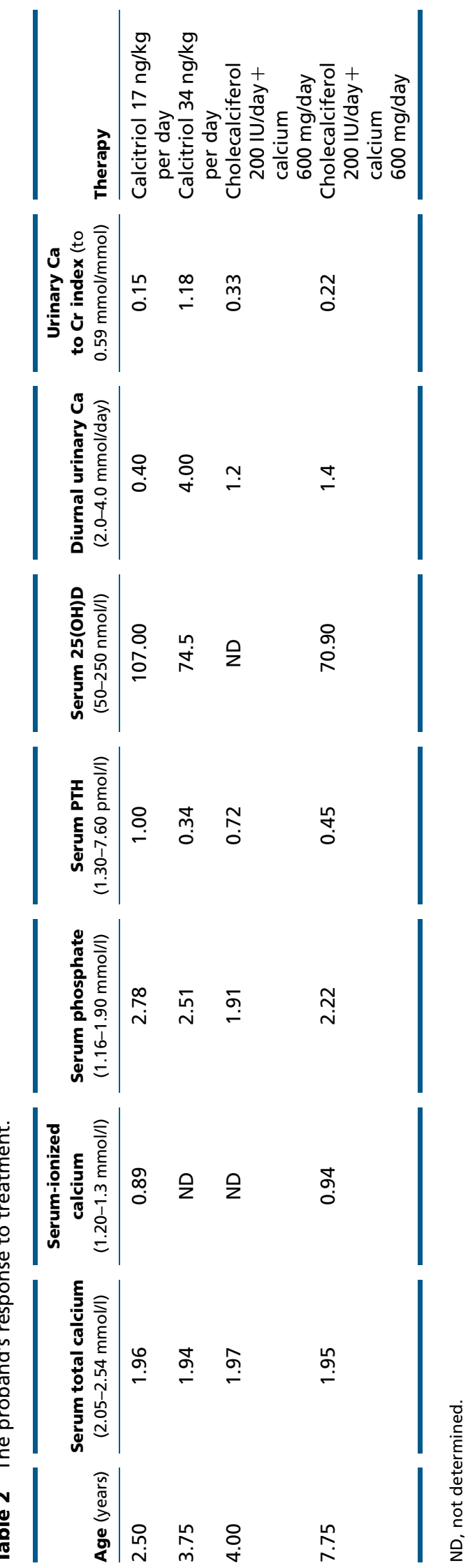

The CASR C-tail extends from amino acid 863-1078, and the proximal part is critical for cell signaling $(19,25$, 26), but additional sequences within both proximal and distal parts of the C-tail are important for cell surface expression, desensitization, internalization, and downregulation of the receptor. Three common polymorphisms, A986S, R990G and Q1011E, in the C-tail are associated with altered blood calcium levels and/or urinary calcium excretion $(27,28)$. A unique secondary structure, a 15 amino acid $\alpha$-helical stretch from residue 877-891, may be required for efficient trafficking of the CASR to the cell surface (25). Phosphorylation at T888 by protein kinase $\mathrm{C}$ is important for desensitization of the receptor and a mutant $(\mathrm{T} 888 \mathrm{M})$ that is unable to be phosphorylated causes ADH (29).

A long PEST-like sequence motif (rich in proline, glutamine, serine and threonine) within amino acids 920-970 of the C-tail directs lysosomal degradation and regulates cell surface receptor level (30) with the latter property also influenced by an arginine-rich motif, R890R898 (31). A leucine 1013, leucine 1014 motif in the CASR ICD interacts with the multi-subunit adaptor protein 2 (AP-2) that mediates endocytosis of the CASR. This function was discovered by the recent finding that missense mutations in the sigma $(\sigma)$ subunit of AP-2 cause familial hypocalciuric hypercalcemia (FHH) type 3 (OMIM \#600740) in FHH patients lacking mutations in the CASR itself (16). The FHH type 3 AP- $2 \sigma$-subunit mutations cause loss of CASR endocytosis as does mutation of leucines at amino acids 1013 and 1014 in the CASR C-tail that interact with the AP-2 $\sigma$-subunit (16). As these amino acids are within the sequence lost in the particular ADH activating mutations described in this report, the mechanisms whereby the ADH mutations exert their gain-of-function vs how the AP- $2 \sigma$-subunit FHH type 3 mutations exert their loss of function will require further study.

With respect to cellular signaling, in a previous study, the freshwater fish tilapia CASR that has a truncated ICD of 96 amino acids lacking the distal part of the mammalian CASR ICD, phosphorylated ERK1/2 via the MAPK pathway in response to increases in extracellular calcium (21). The authors of that study commented that this might be unexpected given reports of binding of the scaffolding protein filamin-A to the distal part of the CASR ICD as a requirement for MAPK activation (32). In the present study, we confirm that human ADH mutant CASRs having a truncated or deleted C-tail, del2703-2710 or del26823224 , that lack the putative filamin A binding site, clearly support phosphorylation of ERK1/2 in response to ligand receptor activation. 
In the proband described here, no symptoms of hypocalcemia have manifested to date, and in her father, the first symptoms occurred at age of 30 years. Wide variability in the clinical presentation has been reported in other $\mathrm{ADH}$ patients, ranging from severe seizures to the total absence of symptoms. The severity of the presentation is inversely related to the serum calcium concentration (6), and a clear link between relative clinical biochemistries and the behavior of particular mutant receptors in vitro has been made in some studies but not others $(6,33,34)$. Also, as patients within the same family can exhibit differing clinical presentations, the potential influence of other genetic or non-genetic factors is suggested (6).

Treatment of the hypocalcemia is especially challenging in $\mathrm{ADH}$ patients relative to hypoparathyroidism of other aetiologies. Treatment with vitamin $\mathrm{D}$ metabolites as is normal in hypoparathyroid hypocalcemia may fail to raise the serum calcium level but excessively stimulate urinary calcium excretion. It can be noted that CASR gene expression is upregulated by active vitamin $\mathrm{D}$ in the parathyroid gland and kidney tubules (35). In $\mathrm{ADH}$ patients, calcitriol treatment may increase expression of the already active CASR in renal tubules leading to nephrocalcinosis, nephrolithiasis and renal damage $(7,36)$. Use of vitamin $\mathrm{D}$ derivatives and their dosages should be carefully considered and the calciuria strictly monitored $(6,7)$. In our proband, the increasing doses of calcitriol led to increased urinary calcium excretion rate but hypocalcemia persisted. Treatment was switched from calcitriol to low-dose calcium and vitamin $\mathrm{D}_{3}$, leading to normalization of calciuria without change in serum calcium. This strategy allowed for the maintenance of a stable serum calcium level minimizing development of clinical symptoms while keeping the calcium excretion rate below which would cause nephrocalcinosis. In a few cases of ADH due to CASR mutations, the long-term use of human PTH has been shown to be of benefit $(37,38)$. In addition, the potential for using calcilytics, compounds that desensitize the CASR, has recently been demonstrated in mouse models of $\operatorname{ADH}(39,40)$.

Finally, there is a high frequency of de novo mutations in $\mathrm{ADH}(6,41)$, and as for other autosomal disorders $(42$, $43)$, as many as $20 \%$ of these may be examples of mosaic mutations that go undetected during routine mutation analysis. In an $\mathrm{ADH}$ family that we studied previously, although the unaffected mother was of apparently normal genotype by routine mutation testing, upon more sensitive analysis, we found that she was mosaic for the activating CASR mutation present in two of her $\mathrm{ADH}-$ affected sons (44). Therefore, the presence of mosaicism could be considered in any $\mathrm{ADH}$ family in which a mutation had apparently arisen de novo. In the present case, examination of both the paternal grandparents, by evaluating multiple subclones of the CASR exon 7 PCR product from their leukocyte DNA, did not provide evidence of mosaicism in either them. However, heterozygosity for the mutation in the proband was confirmed.

In conclusion, we describe a novel naturally occurring deletion mutation within the CASR that apparently arose de novo in the father of the $\mathrm{ADH}$ proband. The functional analysis suggests that the cytoplasmic tail of the CASR contains determinants that regulate the attenuation of signal transduction. Early molecular analysis of the CASR gene in patients with isolated idiopathic hypoparathyroidism is strongly recommended because of its relevance to clinical outcome and treatment choice.

Declaration of interest

The authors declare that there is no conflict of interest that could be perceived as prejudicing the impartiality of the research reported.

\section{Funding}

The study was supported by the Czech Ministry of Education (grants MSM 0021620814 and 0021620819 ) and by the Czech Ministry of Health's Project for Conceptual Development of Research Organization no. 00064203 (University Hospital Motol, Prague, Czech Republic) and by a Canadian Institutes of Health Research (CIHR) operating grant (to G N Hendy), a CIHR Strategic Training Program in Skeletal Health scholarship and a McGill University Hospital Centre Research Institute fellowship (to M Grant).

\section{Acknowledgements}

We thank all the family members for their participation. We thank Dr Lucie Canaff and Ms Xiang Zhou for advice and technical support.

\section{Electronic database URLs}

Online Mendelian Inheritance in Man (OMIM), http://www.ncbi.nlm.nih. gov/; and calcium-sensing receptor mutation database, http://www.casrdb. mcgill.ca.

\section{References}

1 Hendy GN \& Cole DE. Familial Isolated Hypoparathyroidism. In Hypoparathyroidism, ch 16, pp 167-175. Eds ML Brandi \& EM Brown. Italia: Springer-Verlag, 2015.

2 Finegold DN, Armitage MM, Galiani M, Matise TC, Pandian MR, Perry YM, Deka YM \& Ferrell RE. Preliminary localization of a gene for autosomal dominant hypoparathyroidism to chromosome 3q13. Pediatric Research 199436 414-417. (doi:10.1203/00006450199409000-00024)

3 Janicic N, Soliman E, Pausova Z, Seldin MF, Riviere M, Szpirer J \& Hendy GN. Mapping of the calcium-sensing receptor gene (CASR) to 
human chromosome 3q13.3-21 by fluorescence in situ hybridization, and localization to rat chromosome. Mammalian Genome 19956 798-801. (doi:10.1007/BF00539007)

4 Brown EM, Gamba G, Riccardi D, Lombardi D, Butters RR, Kifor O, Sun A, Hediger M, Lytton J \& Hebert SC. Cloning and characterization of an extracellular $\mathrm{Ca}^{2+}$-sensing receptor from bovine parathyroid. Nature 1993366 575-580. (doi:10.1038/366575a0)

5 Pollak MR, Brown EM, Estep HL, McLaine PN, Kifor O, Park J, Hebert SC, Seidman CE \& Seidman JG. Autosomal dominant hypocalcemia caused by a $\mathrm{Ca}^{2+}$-sensing receptor gene mutation. Nature Genetics 19948 303-307. (doi:10.1038/ng1194-303)

6 Lienhardt A, Bai M, Lagarde J-P, Rigaud M, Zhang Z, Jiang Y, Kottler M-L, Brown EM \& Garabedian M. Activating mutations of the calcium-sensing receptor: management of hypocalcemia. Journal of Clinical Endocrinology and Metabolism 200186 5313-5323. (doi:10.1210/ jcem.86.11.8016)

7 Pearce SH, Williamson C, Kifor O, Bai M, Coultard MG, Davies M, Lewis-Barned N, McCredie D, Powell H, Kendall-Taylor P et al. A familial syndrome of hypocalcemia with hypercalciuria due to mutations in the calcium-sensing receptor gene. New England Journal of Medicine 1998 335 1115-1122. (doi:10.1056/NEJM199610103351505)

8 Gunn IR \& Gaffney D. Clinical and laboratory features of calciumsensing receptor disorders: a systematic review. Annals of Clinical Biochemistry 200441 441-458. (doi:10.1258/0004563042466802)

9 D'Souza-Li L, Yang B, Canaff L, Bai M, Hanley DA, Bastepe M, Salisbury SR, Brown EM, Cole DE \& Hendy GN. Identification and functional characterization of novel calcium-sensing receptor mutations in familial hypocalciuric hypercalcemia and autosomal dominant hypocalcemia. Journal of Clinical Endocrinology and Metabolism 200287 1309-1318. (doi:10.1210/jc.87.3.1309)

10 Bai M, Trivedi S \& Brown EM. Dimerization of the extracellular calciumsensing receptor (CaR) on the cell-surface of CaR-transfected HEK293 cells. Journal of Biological Chemistry 1998273 23605-23610. (doi:10.1074/jbc.273.36.23605)

11 Jiang Y, Minet E, Zhang Z, Silver PA \& Bai M. Modulation of interprotomer relationships is important for activation of dimeric calcium-sensing receptor. Journal of Biological Chemistry 2004279 14147-14156. (doi:10.1074/jbc.M307422200)

12 Pidasheva S, Grant M, Canaff L, Ercan O, Kumar U \& Hendy GN. Calcium-sensing receptor dimerizes in the endoplasmic reticulum: biochemical and biophysical characterization of CASR mutants retained intracellularly. Human Molecular Genetics 200615 2200-2209. (doi:10.1093/hmg/ddl145)

13 Bai M, Quinn S, Trivedi S, Kifor O, Pearce SH, Pollak MR, Krapcho K, Hebert SC \& Brown EM. Expression and characterization of inactivating and activating mutations in the human $\mathrm{Ca}^{2+} \mathrm{O}$-sensing receptor. Journal of Biological Chemistry 1996271 19537-19545. (doi:10.1074/jbc. 271.32.19537)

14 Garrett JE, Capuano IV, Hammerland LG, Hung BC, Brown EM, Hebert SC, Nemeth EF \& Fuller F. Molecular cloning and functional expression of human parathyroid calcium receptor cDNAs. Journal of Biological Chemistry 1995270 12919-12925. (doi:10.1074/jbc.270.21. 12919)

15 Breitwieser GE. The calcium-sensing receptor life cycle: trafficking, cell-surface expression, and degradation. Best Practice \& Research. Clinical Endocrinology \& Metabolism 201327 303-313. (doi:10.1016/j. beem.2013.03.003)

16 Nesbit MA, Hannan FM, Howles SA, Reed AA, Cranston T, Thakker CE, Gregory L, Rimmer AJ, Rust N, Graham U et al. Mutations in AP2S1 cause familial hypocalciuric hypercalcemia type 3. Nature Genetics 2013 45 93-97. (doi:10.1038/ng.2492)

17 Obermannova B, Banghova K, Sumnik Z, Dvorakova HM, Belka J, Fenci F, Kolouskova S, Cinek O \& Lebl J. Unusually severe phenotype of neonatal primary hyperparathyroidism due to a heterozygous inactivating mutation in the CASR gene. European Journal of Pediatrics 2009 168 569-573. (doi:10.1007/s00431-008-0794-y)
18 Lienhardt A, Garabédian M, Bai M, Sinding C, Zhang Z, Lagarde JP, Boulesteix J, Rigaud M, Brown EM \& Kottler ML. A large homozygous or heterozygous in-frame deletion within the calcium-sensing receptor's carboxylterminal cytoplasmic tail that causes autosomal dominant hypocalcemia. Journal of Clinical Endocrinology and Metabolism 200085 1695-1702.

19 Bai M, Janicic N, Trivedi S, Quinn SJ, Cole DE, Brown EM \& Hendy GN. Markedly reduced activity of mutant calcium-sensing receptor with an inserted Alu element from a kindred with familial hypocalciuric hypercalcemia and neonatal severe hyperparathyroidism. Journal of Clinical Investigation 199799 1917-1925. (doi:10.1172/JCI119359)

20 D'Souza-Li L, Canaff L, Janicic N, Cole DE \& Hendy GN. An acceptor splice site mutation in the calcium-sensing receptor (CASR) gene in familial hypocalciuric hypercalcemia and neonatal severe hyperparathyroidism. Human Mutation 200118 411-421. (doi:10.1002/humu.1212)

21 Loretz CA, Pollina C, Hyodo S, Takei Y, Chang W \& Shoback D. cDNA cloning and functional expression of a $\mathrm{Ca}^{2+}$ sensing receptor with truncated C-terminal tail from the Mozambique Tilapia (Oreochromis mossabicus). Journal of Biological Chemistry 2004279 53288-53297. (doi:10.1074/jbc.M410098200)

22 Zajickova K, Vrikova J, Canaff L, Pawelek PD, Goltzman D \& Hendy GN. Identification and functional characterization of a novel mutation in the calcium-sensing receptor gene in familial hypocalciuric hypercalcemia: modulation of clinical severity by vitamin D status. Journal of Clinical Endocrinology and Metabolism 200792 2616-2623. (doi:10.1210/ jc.2007-0123)

23 Lienhardt A, Young J, Largarde J, Bai M, Sinding C, Zhang Z \& Lagarde JP. New type of calcium-sensing receptor mutation leading to isolated hypoparathyroidism. In Program and Abstracts of the Endocrine Society 83rd Annual Meeting P1-504, 2001.

24 Hannan FM, Nesbit MA, Zhang C, Cranston T, Curley AJ, Harding B, Fratter C, Rust N, Christie PT, Turner JJ et al. Identification of 70 calcium-sensing receptor mutations in hyper- and hypo-calcaemic patients: evidence for clustering of extracellular domain mutations at calcium-binding sites. Human Molecular Genetics 201221 2768-2778. (doi:10.1093/hmg/dds105)

25 Ray K, Fan GF, Goldsmith PK \& Spiegel AM. The carboxyl terminus of the human calcium receptor: requirements for cell-surface expression and signal transduction. Journal of Biological Chemistry 1997272 31355-31361. (doi:10.1074/jbc.272.50.31355)

26 Chang W, Pratt S, Chen TH, Bourguignon L \& Shoback D. Amino acids in the cytoplasmic C-terminus of the parathyroid $\mathrm{Ca}^{2+}$-sensing receptor mediate efficient cell-surface expression and phospholipase C activation. Journal of Biological Chemistry 2001276 44129-44136. (doi:10.1074/jbc.M104834200)

27 Scillitani A, Guarnieri V, De Geronimo S, Muscarella LA, Battista C, D'Agruma L, Bertoldo F, Florio C, Minisola S, Hendy GN et al. Blood ionized serum calcium is associated with clustered polymorphisms in the carboxyl-terminal tail of the calcium-sensing receptor. Journal of Clinical Endocrinology and Metabolism 200489 5634-5638. (doi:10.1210/jc.2004-0129)

28 Vezzoli G, Terranegra A, Arcidiacono T, Biasion R, Coviello D, Syren ML, Paloschi V, Gianni S, Mignogna G, Rubinacci A et al. R990G polymorphism of calcium-sensing receptor does produce a gain of function and predispose to hypercalciuria. Kidney International $2007 \mathbf{7 1}$ 1155-1162. (doi:10.1038/sj.ki.5002156)

29 Lazarus S, Pretorius CJ, Khafagi F, Campion KL, Brennan SC, Conigrave AD, Brown EM \& Ward DT. A novel mutation in the primary protein kinase $\mathrm{C}$ phosphorylation site in the calcium-sensing receptor causes autosomal dominant hypocalcemia. European Journal of Endocrinology/European Federation of Endocrine Societies 2011164 429-435. (doi:10.1530/EJE-10-0907)

30 Zhuang X, Northup JK \& Ray K. Large putative PEST-like sequence motif at the carboxyl tail of human calcium receptor directs lysosomal 
degradation and regulates cell surface receptor level. Journal of Biological Chemistry 2012287 4165-4176. (doi:10.1074/jbc.M111.271528)

31 Stepanchick A, McKenna J, McGovern D, Huang Y \& Breitwieser GE. Calcium-sensing receptor mutations implicated in pancreatitis and idiopathic epilepsy syndrome disrupt an arginine-rich retention motif. Cellular Physiology and Biochemistry 201026 363-374. (doi:10.1159/ 000320560)

32 Hjälm G, MacLeod RJ, Kifor O, Chattopadhyay N \& Brown EM. FilaminA binds to the carboxyl-terminal tail of the calcium-sensing receptor, an interaction that participates in CaR-mediated activation of mitogenactivated protein kinase. Journal of Biological Chemistry 2001276 34860-34867.

33 Kinoshita Y, Hori M, Taguchi M, Watanabe S \& Fukomoto S. Functional activities of mutant calcium-sensing receptors determine clinical presentations in patients with dominant hypocalcemia. Journal of Clinical Endocrinology and Metabolism 201499 E363-E368. (doi:10.1210/jc.2013-3430)

34 Letz S, Rus R, Haag C, Dörr HG, Schnabel D, Möhlig M, Schulze E, Frank-Raue K, Raue F, Mayr B et al. Novel inactivating mutations of the calcium-sensing receptor: the calcilytic NPS-2143 mitigates excessive signal transduction of mutant receptors. Journal of Clinical Endocrinology and Metabolism 201095 E229-E233. (doi:10.1210/ jc.2010-0651)

35 Canaff L \& Hendy GN. Human calcium-sensing receptor gene. Vitamin D response elements in promoters P1 and P2 confer transcriptional responsiveness to 1,25-dihydroxyvitamin D. Journal of Biological Chemistry 2002277 30337-30350. (doi:10.1074/jbc.M201804200)

36 El-Hajj Fuleihan G, Seifter J, Scott J \& Brown EM. Calcium-regulated renal calcium handling in healthy men: relationship to sodium handling. Journal of Clinical Endocrinology and Metabolism 199883 2366-2372.

37 Mittelman SD, Hendy GN, Fefferman RA, Canaff L, Mosesova I, Cole DE, Burkett L \& Geffner ME. A hypocalcemic child with a novel activating mutation of the calcium-sensing receptor gene: successful treatment with recombinant human parathyroid hormone.
Journal of Clinical Endocrinology and Metabolism 200691 2474-2479. (doi:10.1210/jc.2005-2605)

38 Theman TA, Collins MT, Dempster DW, Zhou H, Reynolds JC, Brahim JS, Roschger P, Klaushofer K \& Winer KK. PTH(1-34) replacement therapy in a child with hypoparathyroidism caused by a sporadic calcium receptor mutation. Journal of Bone and Mineral Research 200924 964-973. (doi:10.1359/jbmr.081233)

39 Dong B, Endo I, Ohnishi Y, Kondo T, Hasegawa T, Amizuka N, Kiyonari H, Shioi G, Abe M, Fukumoto $S$ et al. Calcilytic ameliorates abnormalites of mutant calcium-sensing receptor (CaSR) knock-in mice mimicking autosomal dominant hypocalcemia (ADH). Journal of Bone and Mineral Research 201530 1980-1993. (doi:10.1002/jbmr.2551)

40 Hannan FM, Walls GV, Babinsky VN, Nesbit MA, Kallay E, Hough TA, Fraser WD, Cox RD, Hu J, Spiegel AM et al. The calcilytic agent NPS 2143 rectifies hypocalcemia in a mouse model with an activating calcium sensing receptor (CaSR) mutation: relevance to autosomal dominant hypocalcemia type 1 (ADH1). Endocrinology 2015156 3114-3121. (doi:10.1210/en.2015-1269)

41 Hendy GN, Guarnieri V \& Canaff L. Calcium-sensing receptor and associated diseases. Progress in Molecular Biology and Translational Science 200989 31-95. (doi:10.1016/S1877-1173(09)89003-0)

42 Verhoef S, Bakker L, Tempelaars AM, Hesseling-Janssen AL, Mazurcak T, Jowiak S, Fois A, Bartalini G, Zonnenberg BA, van Essen AJ et al. High rate of mosaicism in tuberous sclerosis complex. American Journal of Human Genetics 199964 1632-1637. (doi:10.1086/ 302412)

43 Leuer M, Oldenberg J, Laverrgne J-M, Ludwig M, Fregin A, Eigel A, Ljung R, Goodeve A, Peak I \& Olek K. Somatic mosaicism in hemophilia A: a fairly common event. American Journal of Human Genetics 200169 75-87. (doi:10.1086/321285)

44 Hendy GN, Minutti C, Canaff L, Pidasheva S, Yang B, Nouhi Z, Zimmerman D, Wei C \& Cole DE. Recurrent familial hypocalcemia due to germline mosaicism for an activating mutation of the calciumsensing receptor gene. Journal of Clinical Endocrinology and Metabolism 200388 3674-3681. (doi:10.1210/jc.2003-030409)

Received 12 December 2015

Revised version received 8 January 2016

Accepted 12 January 2016 